\title{
Effect of Feeding Methods on the Astaxanthin Production by Phaffia rhodozyma in fed-batch Process
}

\author{
Danilo Gomes Moriel $^{1}$, Miriam Blumel Chociai ${ }^{1}$, Iara Maria Pereira Machado ${ }^{1}$, José \\ Domingos Fontana $^{2}$ and Tania Maria Bordin Bonfim ${ }^{*}$ \\ ${ }^{1}$ Laboratório de Enzimologia e Tecnologia das Fermentações; ${ }^{2}$ Biomass Chemo/Biotechnology Laboratory; \\ Departamento de Farmácia; Universidade Federal do Paraná; Rua Lothário Meissner, 3400; 80210-170; Curitiba - \\ PR - Brazil
}

\begin{abstract}
The effect of feeding methods on the production of astaxanthin by the yeast Phaffia rhodozyma ATCC 24202 was studied, using continuous and pulsed fed-batch processes and low cost materials as substrates (sugar cane juice and urea). In continuous fed-batch processes, a cellular astaxanthin concentration of $383.73 \mu \mathrm{g} / \mathrm{g}$ biomass was obtained. But in pulsed fed-batch processes a reduction in the cellular astaxanthin concentration $(303.34 \mu \mathrm{g} / \mathrm{g}$ biomass) was observed. Thus the continuous fed-batch processes could be an alternative to industrial production of astaxanthin, allowing an increase in the biomass productivity without losses on astaxanthin production by the yeast.
\end{abstract}

Key words: Astaxanthin; fed-batch process; Phaffia rhodozyma

\section{INTRODUCTION}

Astaxanthin $\quad\left(3,3^{\prime}\right.$-dihydroxy- $\beta, \beta$ '-carotene-4,4'dione) is a carotenoid widely distributed in nature, found as the main pigment in some crustaceans (shrimp and lobster), fish (trout and salmon), birds (flamingo and scarlet ibis) and microorganisms (the yeast Phaffia rhodozyma and the algae Haematococcus pluvialis) (Johnson and An, 1991). It is mainly used in the trout and salmon farming. Since these animals can not synthesize carotenoids, pigments must be supplemented to their feeds, allowing the assimilation and providing the characteristic pigmentation of these fish, increasing the quality and consumer acceptance in the market-place (Johnson and An, 1991).

Because of the increasing worldwide market, the high cost of synthetic astaxanthin and the need of astaxanthin obtained from natural sources at a low cost and high productivity, the yeast Phaffia rhodozyma has been widely used for astaxanthin production in fed-batch fermentation processes using low cost materials as substrates (An et al., 2001; Chociai et al., 2002; Vazquez et al., 1998). We studied the influence of the feeding method on the astaxanthin production by the yeast Phaffia rhodozyma in continuous and pulsed fed-batch process, using low cost materials (sugar cane juice and urea) as substrates.

\section{MATERIALS AND METHODS}

\section{Microorganism}

The microorganism used was the wild strain Phaffia rhodozyma ATCC 24202.

\footnotetext{
${ }^{*}$ Author for correspondence
} 


\section{Inoculum}

The inoculum was grown on a medium consisting of $(\mathrm{g} / \mathrm{l}) 20$ sucrose, 1 yeast extract and 5 peptone. The inoculum was cultivated in $250 \mathrm{ml}$ Erlenmeyer flasks on a rotatory shaker at $150 \mathrm{rpm}$, $24{ }^{\circ} \mathrm{C}$ for $48 \mathrm{~h}$. This culture was used to inoculate the continuous and pulsed fed-batch processes in order to produce an initial absorbance in the fermentation medium around $0.200(650 \mathrm{~nm})$. It corresponded to an inoculum of 3 to $4 \%$.

\section{Bioreactor set-up}

Fed-batch cultures were grown in a $21 \mathrm{~B}$. Braun Biotech B bioreactor. The initial volume of fermentation medium was 0.81 and the total volume of medium in the bioreactor was between 1.2 and 1.31 after feeding. The composition of the initial fermentation medium was diluted sugar cane juice (20 g total carbohydrates/l) and urea (1 $\mathrm{g} / \mathrm{l})$. The feeding solution was only composed of diluted sugar cane juice, in a total carbohydrate concentration of $100 \mathrm{~g} / \mathrm{l}$. The $\mathrm{pH}$ was controlled at $6.0 \pm 0.2$ by the automatic addition of $1 \mathrm{M} \mathrm{NaOH}$ and $1 \mathrm{M} \mathrm{H}_{2} \mathrm{SO}_{4}$. The aeration was maintained at 1 vvm and the agitation was manually controlled in order to maintain the dissolved oxygen concentration above $40 \%$ of air saturation. The temperature was controlled at $24 \pm 0.5{ }^{\circ} \mathrm{C}$. In the pulsed fed-batch process, were added 23,150 and $214 \mathrm{ml}$ of feeding solution respectively at 24,48 and $72 \mathrm{~h}$ of the fermentation time in order to reestablish the total carbohydrate concentration in the fermentation medium to approximately $20 \mathrm{~g} / \mathrm{l}$. Thus, $387 \mathrm{ml}$ of feeding solution was added in the pulsed fed-batch process. In the continuous fedbatch process, the feed was performed between 16 and $72 \mathrm{~h}$ of fermentation time, using the following flow rates: 16 to $24 \mathrm{~h}: 3 \mathrm{ml} / \mathrm{h} ; 24$ to $32 \mathrm{~h}: 3.75$ $\mathrm{ml} / \mathrm{h} ; 32$ to $40 \mathrm{~h}: 6.125 \mathrm{ml} / \mathrm{h} ; 40$ to $48 \mathrm{~h}: 7.5 \mathrm{ml} / \mathrm{h}$; 48 to $56 \mathrm{~h}: 9.5 \mathrm{ml} / \mathrm{h} ; 56$ to $64 \mathrm{~h}: 11.5 \mathrm{ml} / \mathrm{h}$; and 64 to $72 \mathrm{~h}: 14.125 \mathrm{ml} / \mathrm{h}$. The flow rates were based on the consumption rates obtained in the pulsed fedbatch process studied. Thus, the total amount of feeding solution added in the continuous fed-batch process was $444 \mathrm{ml}$. All the experiments were done in duplicate and the average of the results are shown.

\section{Analytical methods}

Total carbohydrates were measured by the phenolsulfuric method (Dubois et al., 1956). The biomass concentration was measured by optical density
(OD) using spectrophotometer at $650 \mathrm{~nm}$ during all the fermentation time. At the end of the processes, biomass was determined by freezedrying the sample until constant weight. The astaxanthin content was determined by the method described by Bonfim (1999). In this method, the freeze-dried cells were ruptured with $2 \mathrm{ml}$ of DMSO for 30 minutes. Then, $6 \mathrm{ml}$ of acetone was added and agitated vigorously, in order to extract the astaxanthin. The sample was centrifuged and the solvent phase was separated. This process was repeated with the precipitate in order to ensure the extraction of all the astaxanthin content. The two solvent phases obtained were joined and $10 \mathrm{ml}$ of $200 \mathrm{~g} \mathrm{NaCl} / \mathrm{l}$ and $10 \mathrm{ml}$ of petroleum ether were added. After the agitation and separation of the phases, the solvent phase was separated. More 5 $\mathrm{ml}$ of petroleum ether were added to ensure the extraction. The solvent phase was filtrated through $\mathrm{Na}_{2} \mathrm{SO}_{4}$ to eliminate the moisture. The absorbance was measured at $480 \mathrm{~nm}$ and the astaxanthin concentration was calculated using the specific absorption coefficient E1\% $=1600$.

\section{RESULTS AND DISCUSSION}

Fig. 1 shows the variation of total carbohydrate concentration in the fermentation medium during the pulsed fed-batch processes. As observed, the feed was able to reestablish the total carbohydrate concentration to approximately $20 \mathrm{~g} / \mathrm{l}$, avoiding high concentrations in the medium. Bonfim (1999), studying the effect of initial substrate concentration on the production of biomass and astaxanthin by the yeast Phaffia rhodozyma, found that total carbohydrate concentrations above $20 \mathrm{~g} / \mathrm{l}$ led to a reduction on biomass and astaxanthin formation. Johnson and Lewis (1979) and Santopietro et al. (1998) also discovered that the increase on the carbohydrate concentration promoted a reduction on biomass and astaxanthin formation. Reynders et al. (1997) found that it occurred because of the Crabtree effect (which occurs in the presence of fully aerobic conditions and high levels of readily metabolizable sugars, resulting in a reduced biomass yield and formation of ethanol). 


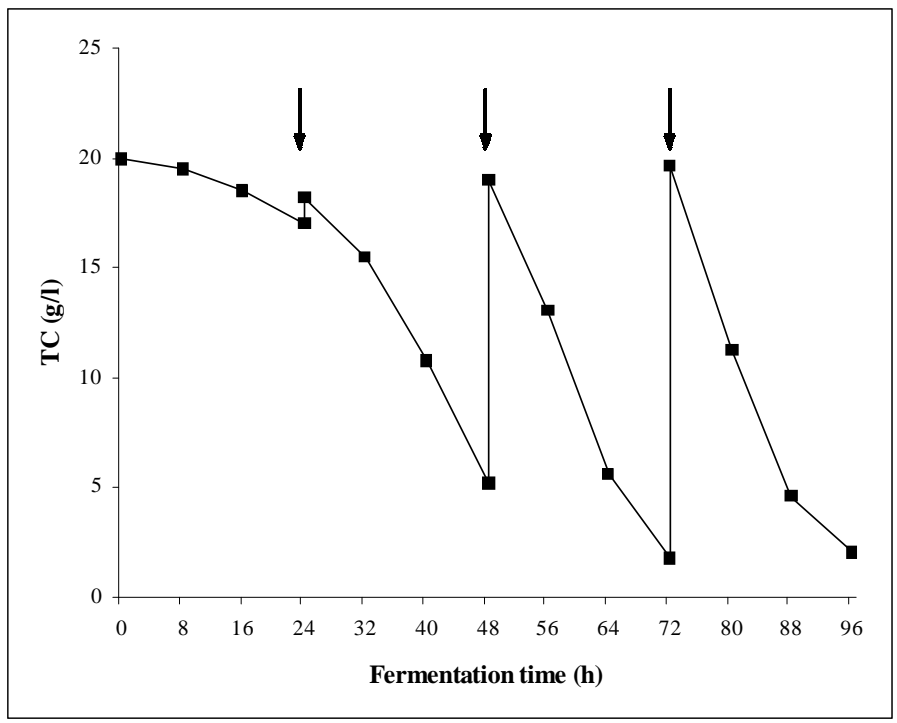

Figure 1 - Variation of total carbohydrate concentration (TC) on pulsed fed-batch process. The arrows indicate the feeding times.

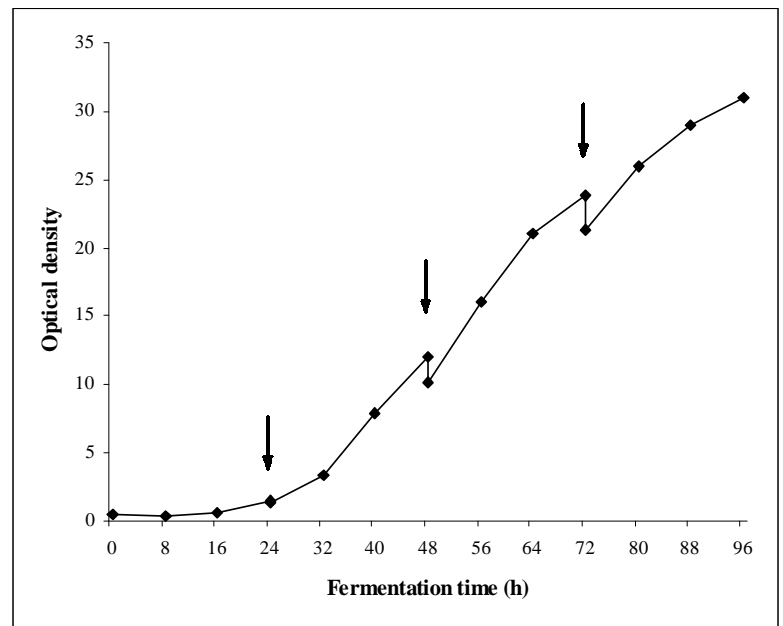

Figure 2 - Biomass formation on pulsed fed-batch process. The arrows indicate the feeding times.

Fig. 2 shows that the addition of feeding solution promoted a dilution on the fermentation medium and, consequently, on the OD. At the $24^{\text {th }}$ hour, dilution could not be observed because of the low amount of feeding solution added. Johnson and Lewis (1979) and Meyer and Du Preez (1993) found that astaxanthin was mainly produced during the exponential phase and the production was also observed in the stationary phase, but at a slow rate. They recommended that the process should be kept in the stationary phase for a while (in order to obtain the maximum astaxanthin productivity). In batch experiments using the same substrates and fermentation conditions, Moriel (2004) found that the cellular astaxanthin concentration did not change after the end of exponential phase and that the stationary phase was not necessary to obtain the maximum cellular astaxanthin concentration.

In the pulsed fed-batch processes, a cellular astaxanthin concentration of $303.34 \mu \mathrm{g} / \mathrm{g}$ biomass, an astaxanthin concentration of $5.69 \mathrm{mg} / \mathrm{l}$, a 
biomass concentration of $18.75 \mathrm{~g} / \mathrm{l}$ and a biomass yield of $0.39 \mathrm{~g}$ biomass $/ \mathrm{g}$ substrate were obtained. The biomass and astaxanthin productivities were $0.195 \mathrm{~g} / \mathrm{l} / \mathrm{h}$ and $0.059 \mathrm{mg} / \mathrm{l} / \mathrm{h}$, respectively. Comparing to batch processes, using the same fermentation conditions (Moriel, 2004), a reduction in the cellular astaxanthin concentration (364.59 to $303.34 \mu \mathrm{g} / \mathrm{g}$ biomass) was observed, besides the increasing in the biomass $(0.072$ to
$0.195 \mathrm{~g} / \mathrm{l} / \mathrm{h})$ and astaxanthin productivities $(0.026$ to $0.059 \mathrm{mg} / \mathrm{l} / \mathrm{h}$ ). Chociai et al. (2002) also observed the same reduction in the cellular astaxanthin concentration, using pulsed fed-batch processes and the same substrates. It showed that great variations in the carbohydrate concentration of the fermentation medium during the process could interfere on the astaxanthin production.

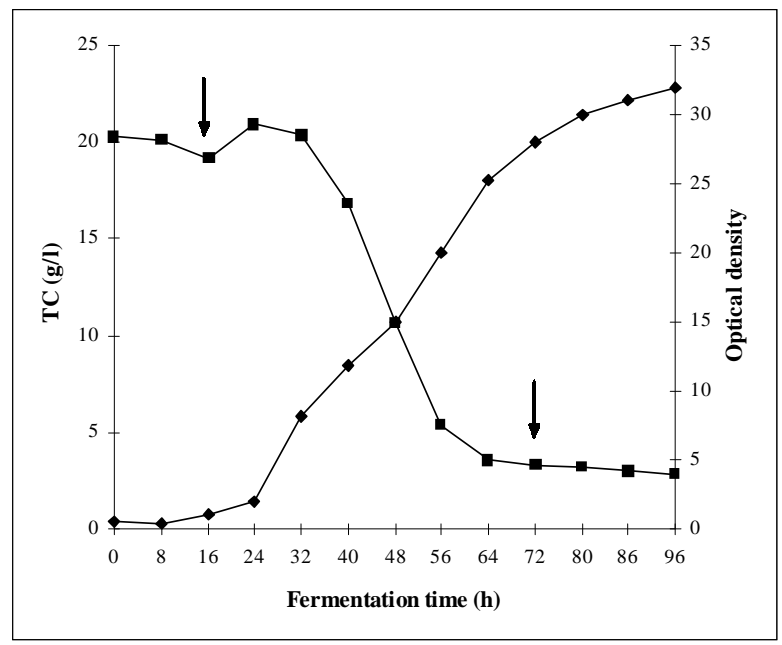

Figure 3 - Biomass formation and variation of total carbohydrate concentration in continuous fed-batch process. ( $)$ total carbohydrates concentration (TC) $(\mathrm{g} / \mathrm{l})$; the end of the feed.

Fig. 3 shows the biomass formation and variation of total carbohydrate concentration in the fermentation medium during continuous fed-batch processes giving a cellular astaxanthin concentration of $383.73 \mu \mathrm{g} / \mathrm{g}$ biomass, astaxanthin concentration of $7.44 \mathrm{mg} / \mathrm{l}$, biomass concentration of $19.35 \mathrm{~g} / \mathrm{l}$ and biomass yield of $0.41 \mathrm{~g}$ biomass $/ \mathrm{g}$ substrate. The biomass and astaxanthin productivities were $0.202 \mathrm{~g} / \mathrm{l} / \mathrm{h}$ and $0.078 \mathrm{mg} / \mathrm{l} / \mathrm{h}$, respectively. Comparing to the pulsed fed-batch processes, the biomass yields and concentrations were very close but a reduction on the cellular astaxanthin concentration was not observed in the continuous fed-batch process, leading to higher astaxanthin concentration and productivity.

\section{CONCLUSIONS}

The utilization of fed-batch processes for the production of astaxanthin by the yeast Phaffia rhodozyma could be an important tool to increase the biomass productivity and, consequently, the astaxanthin productivity as no losses in the cellular astaxanthin concentration were observed. The utilization of continuous feeding showed to be the most efficient feeding method in fed-batch processes, as it did not lead to a reduction in the cellular astaxanthin concentration, as observed in the pulsed feeding. Thus, the utilization of continuous feeding methods for the production of biomass and astaxanthin by the yeast Phaffia rhodozyma could be an important alternative to increase the biomass productivity without losses in the cellular astaxanthin concentration.

\section{ACKNOWLEDGEMENTS}

The financial support of CAPES is gratefully acknowledged. 


\section{RESUMO}

O efeito da alimentação na produção de astaxantina pela levedura Phaffia rhodozyma ATCC 24202 foi estudado, utilizando processos descontínuo alimentado com alimentação contínua e intermitente, e matérias-primas de baixo custo como substratos (caldo de cana de açúcar e uréia). Em processos descontínuo alimentado com alimentação contínua, uma concentração celular de astaxantina de $383,73 \mu \mathrm{g} / \mathrm{g}$ biomassa foi obtida. Entretanto, em processos descontínuo alimentado com alimentação intermitente, uma redução na concentração celular de astaxantina $(303,34 \mu \mathrm{g} / \mathrm{g}$ biomassa) foi observada. Desta forma, processos descontínuo alimentado com alimentação contínua poderiam ser uma alternativa na produção industrial de astaxantina, permitindo um aumento na produtividade de biomassa sem perdas na produção de astaxantina pela levedura.

\section{REFERENCES}

An, G. H.; Jang, B. G. and Cho, M. H. (2001), Cultivation of the carotenoid-hyperproducing mutant $2 \mathrm{~A} 2 \mathrm{~N}$ of the red yeast Xanthophyllomyces dendrorhous (Phaffia rhodozyma) with molasses. J. Biosci. Bioeng., 92, 121-125.

Bonfim, T. M. B. (1999), Produção de astaxantina pela levedura Phaffia rhodozyma (Xanthophyllomyces dendrorhous) a partir de meios de cultura de baixo custo. PhD Thesis, Universidade Federal do Paraná, Curitiba, Brazil.

Chociai, M. B.; Machado, I. M. P.; Fontana, J. D.; Chociai, J. G.; Busato, S. B. and Bonfim, T. M. B. (2002), Cultivo da levedura Phaffia rhodozyma (Xanthophyllomyces dendrorhous) em processo descontínuo alimentado para produção de astaxantina. Brazilian J. Pharm. Sci., 38, 457-462.

Dubois, M.; Gilles, K. A.; Hamilton, J. K.; Rebers, P. A. and Smith, F. (1956), Colorimetric method for determination of sugars and related substances. Anal. Chem., 28, 350-356.

Johnson, E. A. and An, G. H. (1991), Astaxanthin from microbial sources. Crit. Rev. Biotechnol. 11, 297-326.

Johnson, E. A. and Lewis, M. J. (1979), Astaxanthin formation by the yeast Phaffia rhodozyma. J. Gen. Microbiol., 115, 173-183.

Meyer, P. S. and Du Preez, J. C. (1993), Effect of acetic acid on astaxanthin production by Phaffia rhodozyma. Biotechnol. Lett., 15, 919-924.
Moriel, D. G. (2004), Otimização da produção de biomassa e astaxantina pela levedura Phaffia rhodozyma utilizando processo descontínuo alimentado. Master Thesis, Universidade Federal do Paraná, Curitiba, Brazil.

Reynders, M. B.; Rawlings, D. E. and Harrison, S. T. L. (1997), Demonstration of the Crabtree effect in Phaffia rhodozyma during continuous and fed-batch cultivation. Biotechnol. Lett., 19, 549-552.

Santopietro, L. M. D.; Spencer, J. F. T. and Sineriz, F. (1998), Fed-batch and continuous culture of Phaffia rhodozyma (Xanthophyllomyces dendrorhous). Folia Microbiol., 43, 169-172.

Vazquez, M.; Santos, V. and Parajo, J. C. (1998), Fedbatch cultures of Phaffia rhodozyma in xylosecontaining media made from wood hydrolysates. Food Biotechnol., 12, 43-55.

Received: December 18, 2003; Revised: June 28, 2004 Accepted: March 03, 2005. 